\title{
Synchrotron X-ray diffraction investigation of the effect of cryogenic treatment on the microstructure of Ti-6Al-4V
}

Meng, Yichen; Villa, Matteo; Dahl, Kristian V.; Christiansen, Thomas L.; Somers, Marcel A. J.

Published in:

Applied Surface Science

Link to article, DOI:

10.1016/j.apsusc.2019.144087

Publication date:

2020

Document Version

Peer reviewed version

Link back to DTU Orbit

Citation (APA):

Meng, Y., Villa, M., Dahl, K. V., Christiansen, T. L., \& Somers, M. A. J. (2020). Synchrotron X-ray diffraction investigation of the effect of cryogenic treatment on the microstructure of Ti-6Al-4V. Applied Surface Science, 502, [144087]. https://doi.org/10.1016/j.apsusc.2019.144087

\section{General rights}

Copyright and moral rights for the publications made accessible in the public portal are retained by the authors and/or other copyright owners and it is a condition of accessing publications that users recognise and abide by the legal requirements associated with these rights.

- Users may download and print one copy of any publication from the public portal for the purpose of private study or research.

- You may not further distribute the material or use it for any profit-making activity or commercial gain

- You may freely distribute the URL identifying the publication in the public portal 


\title{
Synchrotron X-ray diffraction investigation of the effect of cryogenic treatment on the microstructure of Ti-6Al-4V
}

\author{
Yichen Meng, Matteo Villa, Kristian V. Dahl, Thomas L. Christiansen, Marcel A.J. Somers \\ Technical University of Denmark, Department of Mechanical Engineering, 2800, Kgs. Lyngby, \\ Denmark, DK
}

Keywords: titanium alloy, Ti-6Al-4V, heat treatment, phase transformation, cryogenic treatment, synchrotron X-ray diffraction

\begin{abstract}
Ti-6Al-4V was (intercritically) annealed at various temperatures in the range 1000-1250 $\mathrm{K}$ with

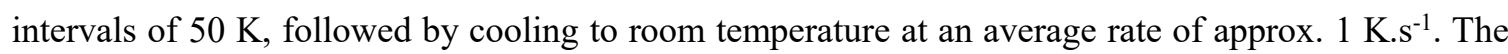
heat treatment procedure was intended to systematically vary the microstructure and alter the thermal stability of the $\beta$ phase through the partitioning of the alloying elements between $\alpha$ and $\beta$ phases. The annealing treatment was followed by cryogenic treatment, CT, which consisted of immersion of the samples in boiling nitrogen for durations ranging from 5 minutes to 24 hours, followed by re-heating in air. The heat-treated material was characterized ex-situ applying light optical microscopy (LOM), synchrotron X-ray diffraction (S-XRD), and hardness Vickers indentation. A set of samples not subjected to cryogenic treatment was taken as reference. LOM revealed that the material's microstructure after heat treatment consisted of a fraction of primary $\alpha$ grains and regions of lamellar $\alpha / \beta$ structure. S-XRD showed that the fraction of retained $\beta$ was largest, approx. $7 \%$, for the material treated at the highest applied annealing temperature, i.e. $1250 \mathrm{~K}$, and decreased to $2 \%$ with a reduction of the annealing temperature. Hardness values varied in the range 300-330 HV and did not show a measurable effect of the annealing temperature. The applied techniques did not reveal any measurable effect of cryogenic treatment, neither on the microstructure, nor on the hardness. Additionally, CT had no measurable effect neither on the lattice parameters of the phases, nor on the density of crystallographic defects in the material. These observations are inconsistent with literature data, which report various effects of $\mathrm{CT}$ on the microstructure and on the mechanical properties of Ti-6Al-4V, and are attributed to a pronounced stability of the retained $\beta$ phase against its conversion into $\alpha^{\prime}$ martensite during $\mathrm{CT}$ in the present heat treatment conditions.
\end{abstract}

\section{Introduction}


There is increased focus on the use of titanium and its alloys for applications that require a combination of outstanding corrosion resistance and high mechanical strength. The properties of titanium and its alloys are dictated by the microstructure of the material, which can be tailored by heat treatment. Microstructure optimization in titanium and titanium alloys has been the topic of extensive research [1]. However, certain aspects of the heat treatment of titanium alloys, such as the effect of introducing a cryogenic step in the thermal cycle, remain largely uninvestigated.

Combined with the traditional heat treatment cycle, cryogenic treatment (CT) is extensively applied to improve the performance of metallic parts, especially martensitic steel components. Conventional heat treatment of martensitic steel consists of a high temperature step to form (soft) austenite, followed by quenching to room temperature to transform the austenite into (hard) martensite and by tempering to promote the decomposition of the martensite into ferrite and carbides. Martensite starts to form during quenching upon reaching a composition dependent critical temperature, the martensite start temperature, Ms, and the transformation, which is associated with a volume expansion, continues during continuous cooling. Ideally, a full conversion of the austenite into martensite is desired, but often this is not practically possible due to the strong austenite stabilizing effect of C [2]. Cryogenic treatment of steel minimizes the fraction of retained austenite [2], resulting in increased hardness [2] and improved dimensional stability [3, 4]. Additionally, various authors reported that the evolution of the internal stresses during long time storage of steel at cryogenic temperatures yields improved wear resistance [5-12].

Analogously, in Ti alloys, $\beta$ is the high temperature phase and $\alpha$ is the low temperature phase. The martensite structure that forms by fast cooling of $\beta$ is denoted $\alpha^{\prime}$. The combination of $\alpha$ stabilizing elements, such as $\mathrm{Al}, \mathrm{O}, \mathrm{N}$ and $\mathrm{C}$, and $\beta$ stabilizing elements, such as $\mathrm{Mo}, \mathrm{V}, \mathrm{Ta}$ and $\mathrm{Nb}$, determines the stability of the $\beta$ phase against its transformation into $\alpha / \alpha^{\prime}[1]$. A high fraction of $\beta$-stabilizing elements enhances the stability of $\beta$ and lowers both the $\beta$ transus temperature (the temperature above which $\beta$ is the only thermodynamically stable phase) and the Ms; $\alpha$-stabilizers have the opposite effect, they increase both $\beta$ transus temperature and Ms [13]. Only a few studies on the effect of CT on the microstructure, and consequently, on the properties of titanium alloys are reported in the literature [14$18]$. These studies deal with metastable $\beta$ Ti alloys $[16,17]$ and $\alpha / \beta$ Ti- $6 \mathrm{Al}-4 \mathrm{~V}$, also known as Grade 5 $\mathrm{Ti}[14,15,18]$, and its low interstitial equivalent Ti-6Al-4V ELI.

CT of metastable $\beta$ alloys is a relatively simple case. Metastable $\beta$ alloys are materials where the $\beta$ stability is tailored such that this phase can transform martensitically upon plastic deformation at room temperature. This implies that $\mathrm{Ms}$ is intentionally kept slightly lower than room temperature in these grades. This characteristic behavior yields alloys with high strength and high elongation that can be classified as transformation-induced plasticity, TRIP, Ti alloys [19]. Gu et al. [16] demonstrated martensite formation during CT in metastable $\beta$ titanium alloy Ti-15Mo-3Al-2.7Nb-0.2Si. Similarly, $\mathrm{Xu}$ demonstrated that a martensitic transformation takes place during $\mathrm{CT}$ of metastable $\beta$ titanium alloys Ti-10V-2Cr-3Al, Ti-10V-1Fe-3Al and Ti-10V-2Fe-3Al-B [17], with the metastable $\beta$ phase that transformed into martensite upon CT. Depending on the relative stability of the $\beta$ phase against thermal transformation into martensite, initiated at Ms upon cooling, the effect of cryogenic treatment can be predicted. 
The case of $\alpha / \beta$ alloys is more complex than the case of metastable $\beta$-Ti. Element partitioning between $\alpha$ and $\beta$ phase can take place during annealing and/or cooling of the material, resulting in a dependence of the stability of (retained) $\beta$ on the thermal history. In Grade $5 \mathrm{Ti}$, the fraction of $\beta$ phase at the annealing temperature decreases with decreasing annealing temperature in the intercritical region (i.e. for temperatures lower than the $\beta$ transus), while the $V$ content in the $\beta$ phase increases [20]. As the annealing temperature decreases below approx. $950 \mathrm{~K}$, the $\beta$ phase will be stable and is retained upon quenching to room temperature. For example, it is reported for Ti-6Al-4V, that the chemical composition of the $\beta$ phase after quenching from equilibrium at $873 \mathrm{~K}$ is Ti-2Al-16V [20] which can be regarded as a $\beta$ alloy (i.e. $\beta$ is expected stable down to cryogenic temperatures) [21]. However, the cooling conditions will play an important role in this respect: On slow cooling from annealing temperatures higher than $950 \mathrm{~K}$, significant redistribution of the alloying elements takes place [19, 22]. This results in regions of stable $\beta$ distributed within a matrix of $\alpha$; these regions are retained after cooling to room temperature. Contrary, on fast cooling, $\beta$ remains unstable and is completely converted into $\alpha / \alpha^{\prime}$. Clearly, under certain conditions, retained $\beta$ can be considered borderline with respect to a transformation into $\alpha^{\prime}$ during cooling to room temperature; consequently the material will transform if CT is applied. Additionally, the presence of two phases introduces additional complexity in the evaluation of the effect of $\mathrm{CT}$ on the microstructure and properties. In fact, $\alpha$ and $\beta$ have different coefficients of thermal expansion and different mechanical properties. During $\mathrm{CT}$, the temperature can vary as much as $200 \mathrm{~K}$. It is very likely that the mechanical interaction between $\alpha$ and $\beta$ regions introduces a significant amount of plasticity (i.e. crystallographic defects) in the material, resulting in significant micro-stresses which will influence the mechanical behavior of CT parts.

The effect of CT on Grade 5 and Grade 5 ELI was investigated by Gu et al. [14, 15, 18]. In Ref. [18], Grade $5 \mathrm{Ti}$ in annealed (undefined) condition was treated applying a controlled cryogenic thermal cycle to $93 \mathrm{~K}$ followed by a stress relief treatment at $443 \mathrm{~K}$. The authors reported that CT increased the elongation at rupture of the material without impairing its strength. The effect on hardness was negligible. The microstructure of $\mathrm{CT}$ treated materials was investigated by scanning electron microscopy (SEM) and ostensibly revealed a reduction of the number of beta regions concomitantly with an overall increase in average size (i.e. the smaller regions transformed into $\alpha^{\prime}$ ). In Ref. [14], the material under investigation was Grade 5 ELI annealed at $1073 \mathrm{~K}$. Various cryogenic treatments were applied, where the cooling step was continued to temperatures in the range from $193 \mathrm{~K}$ to $77 \mathrm{~K}$ and was followed by storage of the material for 3-72 $\mathrm{h}$ at the cryogenic temperature. Subsequently, the CT samples were stress relieved at $443 \mathrm{~K}$. Data showed a remarkable effect of $\mathrm{CT}$ on the mechanical properties. In particular, long storage of the material at $77 \mathrm{~K}$ seemingly promoted a significant increase in hardness and a significant improvement in wear resistance. Laboratory X-Ray Diffraction (XRD) and SEM showed that CT reduced the number and the overall fraction of the beta regions. XRD also revealed peak broadening, which was attributed to a refinement of the microstructure by CT. Ti G5 ELI grade was also the material under investigation in Ref. [15], where annealed samples (again, no further specified conditions) were subjected to various thermal cycles, including CT at $77 \mathrm{~K}$, followed by precipitation aging in the temperature range 673-923 K. The microstructure evolution and properties resulting from these treatments did not show systematic trends or recognizable patterns, with the exception that the elongation was always increased after $\mathrm{CT}$ and the number of $\beta$ regions was always 
reduced.

The present work aims at contributing to the understanding of the effect of $\mathrm{CT}$ on the microstructure of Ti-6Al-4V. Below the $\beta$ transus temperature, the fraction of $\mathrm{V}$ in the $\beta$ phase increases with decreasing temperature. A high content of $\beta$ stabilizing elements (such as $\mathrm{V}$ ) suppresses the martensitic transformation. On the other hand, $\beta$ phase with a low content of $\mathrm{V}$ renders the $\beta$ phase metastable; this implies that phase transformation at CT temperature is theoretically possible. Additionally, the introduction of crystallographic defects caused by the mechanical interaction of $\alpha$ and $\beta$ phases during $\mathrm{CT}$ is expected. Various annealing temperatures followed by furnace cooling were applied, yielding different compositions and fractions of $\alpha$ and $\beta$ phases. Thereafter, the microstructure of the material was investigated by synchrotron X-ray diffraction (S-XRD), light optical microscopy (LOM), and hardness indentation. S-XRD can also reveal (possible) build-up of internal micro-stresses associated with $\mathrm{CT}$.

\section{Experimental}

\subsection{Material and heat treatment}

The Ti-6Al-4V employed in the present study was produced by S-Tech. Corp. The material was received as a cylindrical rod, $15 \mathrm{~mm}$ in diameter, in a mill annealed condition $(1023 \mathrm{~K}$ for $1 \mathrm{~h}$ followed by air cooling). In this condition, a typical duplex microstructure with fine $\beta$ particles dispersed in the $\alpha$ matrix is obtained. The investigated specimens were discs, $2 \mathrm{~mm}$ in thickness, which were obtained by slicing the rod perpendicular to the rolling direction using a Struers Accutom precision cutting machine. The chemical composition of the material as provided by the supplier is given in Table 1 .

After preparation, samples were subjected to heat treatment. The first heat treatment step consisted of intercritical annealing, where $\alpha$ and $\beta$ phases coexist in thermodynamic equilibrium, in the range $1000-1250 \mathrm{~K}$ with intervals of $50 \mathrm{~K}$. The holding time at the annealing temperature was varied from 1.8 ks to $19.8 \mathrm{ks}$; the higher the temperature, the shorter the treatment time applied. This variation was intended to promote significant partitioning of the alloying elements between $\alpha$ and $\beta$ phases at all treatment temperatures and took into consideration that redistribution of the alloying elements is expected to be slowest at the lowest applied temperature. The treatment was conducted in a horizontal Kanthal-tube furnace with continuous Ar flow (99.999\% purity). To minimize the uptake of oxygen during heat treatment, the furnace was pre-cleaned in hydrogen and the samples were protected by wrapping them in AISI 316 stainless steel foil. Cooling from the annealing temperature to room temperature was also conducted in $\mathrm{Ar}$ and took place at an average rate of $1 \mathrm{~K} \cdot \mathrm{s}^{-1}$. Cryogenic treatment (CT) was initiated directly after the annealing step by immersion of the material in boiling nitrogen, storage in boiling nitrogen for various times and re-heating to room temperature in air. The storage time was varied and was either $0.3 \mathrm{ks}$, (i.e. 5 minutes), or $3.6 \mathrm{ks}$ ( 1 hour) or $84.6 \mathrm{ks}$ (i.e. 1 day). Samples are labelled $5 \mathrm{M}, 1 \mathrm{H}, 1 \mathrm{D}$, respectively. The overall experimental procedure is schematically presented in Fig. 1. Table 2 describes the labelling system adopted.

\subsection{Metallography, hardness measurements and thermodynamic equilibrium predictions}

The microstructure and hardness of the samples were investigated on the cross-sections of the 
specimens. For metallography samples were hot mounted (approx. $450 \mathrm{~K}, 0.3 \mathrm{ks}$ ) in a Struers Prontopress 20 using Durofast resin. Specimens were ground with abrasive paper in the sequence 500 mesh, 1000 mesh and 4000 mesh followed by mechanical polishing with 3 micron diamond and Struers' OP-S. Etching was performed using Keller's reagent $\left(185 \mathrm{~mL} \mathrm{H}_{2} \mathrm{O}+5 \mathrm{~mL} \mathrm{HNO}_{3}(65 \%)+3 \mathrm{~mL} \mathrm{HCl}\right.$ $(32 \%)+4 \mathrm{~mL}$ HF $(10 \%))$ with $20 \mathrm{~s}$ of etching time.

Metallography was performed with an Olympus GX-41 light optical microscope (LOM) equipped with a Leica DFC $450 \mathrm{C}$ camera. Vickers hardness measurements were performed with a Future Tech model FM-700 micro-hardness tester applying $10 \mathrm{~s}$ dwelling time and $500 \mathrm{~g}$ force.

Thermodynamic equilibrium predictions of phase fractions and compositions were calculated using Thermo-Calc version 2018b [23] using the Thermo-Calc Software TCTi titanium alloys database version 1 .

\subsection{Synchrotron X-Ray Diffraction}

Ex-situ synchrotron X-Ray diffraction was performed at the BESSY II synchrotron facility on the EDDI beamline with a white (polychromatic) X-ray beam [24]. In order to optimize the statistics, 10 measurements were performed, $5 \times 2$ times on two different samples treated identically. The scattering angle was fixed at $8^{\circ} 2 \theta$ with a slit size of $2 \times 2 \mathrm{~mm}^{2}$. The recorded spectra were corrected for instrumental effects, using the standard procedure provided by the EDDI beamline scientists. For absorption correction the absorption coefficient $\mu_{\mathrm{m}}(\mathrm{E})$ for pure Ti was used. After subtraction of the background, the diffraction peaks were fitted using pseudo-Voigt profile functions, which provided the position $\mathrm{E}(\mathrm{hkl})$ of all diffraction lines hkl, the intensity of each reflection and the breath of all peaks expressed in terms of integral breath, $\mathrm{I}_{\mathrm{b}}(\mathrm{hkl})$. In energy dispersive $\mathrm{X}$-Ray diffraction, the lattice spacing, $\mathrm{d}(\mathrm{hkl})$, follows from the position of the reflections on the energy scale [25]:

$d(h k l)=\frac{h \cdot c}{2 \cdot \sin \theta \cdot E(h k l)}$

where $\theta$ is the angle between the incident beam and the diffracting family of crystallographic planes, $h$ is Planck's constant, $\mathrm{c}$ is the velocity of light and $\mathrm{E}$ is the energy of incident photons. Quantitative phase analysis was also conducted and was based on the following equations [26]:

$f_{\beta}=1-f_{\alpha}=\left(\frac{1}{n} \sum_{j=1}^{n} \frac{I_{\beta}}{R_{\beta}}\right) /\left[\left(\frac{1}{q} \sum_{j=1}^{q} \frac{I_{\alpha}}{R_{\alpha}}\right)+\left(\frac{1}{n} \sum_{j=1}^{n} \frac{I_{\beta}}{R_{\beta}}\right)\right]$

$R_{\beta}(h k l)=\left(\frac{h \cdot c}{E}\right) \cdot \frac{|F(h k l)| \cdot p(h k l) \cdot e^{-2 M}}{v^{2}}$

where $\mathrm{I}$ is the measured integrated intensity, $\mathrm{f}$ is the volume fraction, $\mathrm{R}$ is the theoretical integrated intensity for a texture-free sample, $\mathrm{p}(\mathrm{hkl})$ is the multiplicity factor, $|\mathrm{F}(\mathrm{hkl})|^{2}$ is the structure factor calculated from tabulated values for pure Ti, $\exp ^{-2 \mathrm{M}}$ is the Debye-Waller factor [27], $v$ is volume of the unit cell and $q$ and $n$ are the number of hkl reflections of $\alpha$ and $\beta$, respectively. The calculated $\mathrm{R}$ values for each diffraction peak are shown in Table 3. The analysis considered all reflections listed in Table 3. Reflections at $\mathrm{E}>75 \mathrm{keV}$ were low in intensity and were therefore excluded from the analysis. At $\mathrm{E}<$ $75 \mathrm{keV}$, the $\alpha$ (103) and $\beta$ (211) peaks were excluded from the analysis due to peak overlap. Moreover, $\alpha(002)$ was omitted because the intensity of the more intense, and partially overlapping, (110) $\beta$ peak, appeared to influence the fit. 
Qualitative evaluation of the effect of CT on the density of crystallographic defects and on the dimension of the $\alpha$ and $\beta$ regions was performed by considering the width of the fitted peaks. To spot variations in these factors, data were plotted following the Williamson-Hall description [28, 29]. Quantitative analysis of the density of crystallographic defects and of the crystallite size requires the evaluation of the instrumental contribution to peak broadening, and the knowledge of the dislocation contrast factors for the various hkl lines. This analysis was beyond the scope of the present work.

\section{Results}

\section{1. $L O M$}

The results of LOM are presented in Figs. 2 and 3. Fig. 2 shows that the material after conventional treatment contains two microstructural features, which are identified as primary $\alpha$, appearing white in Fig. 2, and prior $\beta$, which decomposed into a lamellar $\alpha+\beta$ structure during cooling [30] and appears black in the optical microscope. Additionally, Fig. 2 shows that the overall morphology, phase fractions and size distributions of the two microstructural components change with the annealing temperature. Upon treating at $1000 \mathrm{~K}, \alpha$ shows an irregular structure, which is the remnant of the original soft annealed condition, and the prior $\beta$ areas are practically absent. For the temperature range 1050-1200 $\mathrm{K}$, the morphology of primary $\alpha$ becomes equi-axed; prior $\beta$ phase appears along the grain boundaries of equi-axed $\alpha$ grains. The fraction of prior $\beta$ phase increases with increasing temperature. For annealing temperatures above, say, $1100 \mathrm{~K}$, growth of primary $\alpha$ is relatively fast upon cooling, implying that the fraction of prior $\beta$ originally present at the annealing temperature is not fully reflected in the micrographs. Moreover, starting from $1150 \mathrm{~K}$ (Fig. 2(d)), microstructure coarsening is observed for the Widmanstätten (lamellar) structure. Coarsening is significant for the material treated at $1250 \mathrm{~K}$ (Fig. 2(f)), where prior $\beta$ appears as the dominant structure and primary $\alpha$ is only observed at a few locations at the boundaries of the prior $\beta$ grains. According to the literature [30-32], $1250 \mathrm{~K}$ is a temperature close to the $\beta$ transus temperature in Ti-6Al-4V, which is consistent with the present observation (Fig. 2(f)). However, it must be mentioned that the $\beta$ transus temperature can vary due to variations in the alloying elements, for example, $\mathrm{C}, \mathrm{O}$ and $\mathrm{N}$ within specification limits [32].

After annealing, a part of the samples was subjected to CT. The microstructure of the material that underwent CT for 24 hours (i.e. samples 1D) is shown in Fig. 3. Compared to the micrographs in Fig. 2, no remarkable changes are observed. This is not surprising since the effects of CT on the microstructure, if any, occurs at a scale that is impossible to resolve with LOM, as the changes are expected within the retained $\beta$ regions and/or at the interface between $\beta$ and $\alpha$. Other techniques should be applied to identify these effects.

\subsection{Vickers hardness}

Local microstructural changes may have an effect on the hardness. The results of the Vickers hardness measurements are shown in Fig. 4. Data indicates that the hardness of the material ranges within the interval 300-330 HV. Variations among samples appear minor and do not show a specific pattern versus the applied heat treatment conditions. Hence, neither the annealing temperature, nor the introduction of a CT step has an obvious influence on the hardness of Ti-6Al-4V. In the light of LOM results, that show large variations of the microstructure with the annealing temperature, it is concluded that the different proportions and morphologies of $\alpha$ and $\beta$ phases have no obvious influence on the 
hardness. This observation implies that hardness measurements are unlikely to reveal an effect of CT on the microstructure, if any.

\subsection{Synchrotron X-ray diffraction}

To investigate the effect of $\mathrm{CT}$ on the microstructure, synchrotron X-ray Diffraction was applied. In addition to phase fractions, S-XRD can reveal very small variations of the microstructural features, e.g. crystallographic defects in the sample and the crystallite size; these features are hardly detectable even using advanced electron microscopy techniques. Moreover, when compared with electron microscopy, S-XRD offers better statistics.

S-XRD spectrograms are presented in Fig. 5. Two phases are detected: $\alpha$ - and $\beta$-Ti. Even though the samples showed mild surface oxidation, as revealed by colorations, no titanium oxide was detected. Evidently, the oxygen uptake, which is unavoidable during heat treatment of Ti, was negligible (note that the information depth of S-XRD exceeds $100 \mu \mathrm{m}$ for the present experimental setup). To determine the fraction of $\beta$ phase, quantitative phase analysis was performed, which shows that the volume fraction of $\beta$ phase increases monotonically from approx. $2 \%(1000 \mathrm{~K})$ to approx. $7 \%(1250 \mathrm{~K})$ with increasing annealing temperature (Fig. 6). Regarding the effect of CT, Fig. 6 shows that $\mathrm{CT}$ has no measurable effect on the fraction of $\beta$ phase. Evidently, retained $\beta$ is thermally stable against transformation into $\alpha^{\prime}$ on cooling to, and subsequent holding at, $77 \mathrm{~K}$.

In addition, S-XRD data was used to evaluate the lattice parameters of the $\alpha$ and $\beta$ phases (Fig. 7). The lattice parameter is a function of the chemical composition and of the presence of phase-specific stresses in the material. Fig. 7 shows that the lattice parameter of the b.c.c. $\beta$ phase is smallest for the highest annealing temperature, $1250 \mathrm{~K}$. The lattice parameter increases on reducing the annealing temperatures and a maximum value is reached at $1050 \mathrm{~K}$; at $1000 \mathrm{~K}$ the lattice parameter of $\beta$ is reduced again. For the lattice parameters of h.c.p. $\alpha$-Ti, two distinct regimes are observed: a more or less constant lattice parameter in the temperature range $1100-1250 \mathrm{~K}$ and a notably higher value for the lattice parameter in the range $1000-1050 \mathrm{~K}$; an abrupt change occurs from 1100 to $1050 \mathrm{~K}$. Considering the effect of CT, the data indicates that, within experimental accuracy, CT has no effect on the lattice parameters of either $\beta$ and $\alpha$. This observation was confirmed from the individual positions of the hkl reflections (not shown): again, no effect of $\mathrm{CT}$ was revealed.

Regarding the density of crystallographic defects and the dimensions of the crystallites (i.e. the scale of the microstructure at the nanometer level), this information is derived from the width of the fitted peaks in the XRD spectra. Again, no measurable effects of CT on the width of the XRD peak were detected. By simultaneously taking into account all hkl reflections in the spectra, a Williamson-Hall (W-H) analysis is more sensitive to small variations in the internal structure when compared to single lines evaluation $[28,29]$. In a W-H plot, the peak width, here expressed in terms of measured integral breath $\mathrm{I}_{\mathrm{b}}$, is plotted vs. the position of the hkl reflection on the energy scale, E (Fig. 8(a)); the slope of the straight line fitted though the various data scales with the density of crystallographic defects, while the intercept with the y axis scales inversely proportionally with the crystallite size. The results of the linear regressions are reported in Figs. 8b and c. The analysis shows an effect of the annealing temperature on the internal structure of the material. However, no measurable effect of $\mathrm{CT}$ is detected.

In summary, $\mathrm{S}-\mathrm{XRD}$ indicates that $\mathrm{CT}$ has had no influence on the fraction of retained $\beta$. Moreover, no effect of $\mathrm{CT}$, neither on peak broadening nor on the peak positions was detected, which convincingly 
demonstrates that CT has had no measurable effect on the overall internal structure of the samples, including segregation of elements, build-up of internal stresses, and formation of crystallographic defects as a consequence of CT.

\section{Discussion}

LOM, Vickers hardness measurements and S-XRD were applied to reveal the effect of immersion (and long time storage) in boiling nitrogen on the microstructure of $\alpha / \beta$ Grade $5 \mathrm{Ti}$ subjected to intercritical annealing at various temperatures followed by (moderately) slow cooling to room temperature. The results indicated that $\mathrm{CT}$ has no effect on the microstructure in the investigated samples. This conclusion deviates from that presented by Gu et al. $[14,15,18]$, who reported the observation of broadening of various XRD lines upon $\mathrm{CT}$, which can indicate either the generation of crystallographic defects in the material by $\mathrm{CT}$, or a refinement of the microstructure. Additionally, $\mathrm{Gu}$ et al. $[14,15,18]$ reported that characteristic microstructural defects had formed during $\mathrm{CT}$ in the $\alpha$ structure, as revealed by transmission electron microscopy (TEM). Moreover, a reduction of the fraction of retained $\beta$ with CT was revealed both by XRD and by SEM. Below, the diverging results of the present study and those of $\mathrm{Gu}$ et al. are discussed. In the discussion, the equilibrium fractions of phases and their compositions at the various annealing temperatures, as chosen in the present work, were calculated with Thermo-Calc ${ }^{\mathrm{TM}}$ software. To evaluate the thermal stability of $\beta$ versus its transformation into $\alpha^{\prime}$ martensite on cooling, Ms was calculated from the expression in Ref. [13].

Figs. 9(a) and 9(b) show the mass fractions of the different phases and the chemical compositions of $\beta$ phase at various temperatures under thermodynamic equilibrium. Fig. 9(c) reports Ms as calculated based on the equilibrium composition of the $\beta$ phase at the various temperatures. $\mathrm{Ti}_{3} \mathrm{Al}$, which is stable at temperatures below $900 \mathrm{~K}$, was excluded from the calculations because its formation is kinetically inhibited in the present case (i.e. cooling was too fast for its formation). In fact, this phase was not detected by S-XRD, indicating that its content was below the detection limit.

As follows from Fig. 9(a), Thermo-Calc ${ }^{\mathrm{TM}}$ predicts that the equilibrium mass fractions of $\beta$ phase at the different annealing temperatures are: $10 \%(1000 \mathrm{~K}), 13.7 \%(1050 \mathrm{~K}), 20.6 \%(1100 \mathrm{~K}), 34 \%(1150$ $\mathrm{K}), 60.6 \%(1200 \mathrm{~K})$ and $99.4 \%(1250 \mathrm{~K})$, respectively. The corresponding Ms temperatures are: $373 \mathrm{~K}$, $589 \mathrm{~K}, 765 \mathrm{~K}, 909 \mathrm{~K}, 1024 \mathrm{~K}$ and $1079 \mathrm{~K}$, respectively. The predicted fractions of $\beta$ phase are consistently higher than the fractions of $\beta$ obtained from S-XRD. In fact, the fraction of $\beta$ in Fig. 9(a) should be interpreted as the fraction of prior $\beta$, which roughly corresponds to the complementary fraction of primary alpha as observable in Figs. 2 and 3. The fraction of $\beta$ phase retained at room temperature depends on its intrinsic thermal stability with respect to martensitic transformation into $\alpha^{\prime}$ on cooling, and on the cooling conditions. Provided that no diffusional transformations occur during cooling from the annealing temperature, $\beta$ starts to transform into $\alpha^{\prime}$ at Ms. Typically, the martensitic transformation continues on continuous cooling and is completed approx. $100 \mathrm{~K}$ below Ms. As evident from Fig.(9c), the $\beta$ phase should not be stable during cooling to room temperature for the applied annealing conditions, i.e. no (or very little) $\beta$ should be observed by S-XRD in absence of diffusional phenomena. In the present work though, the presence of retained $\beta$ was clearly observed in all samples. The cooling rate from the annealing temperatures to room temperature was (moderately) low. During (moderately) slow cooling, the (prior) $\beta$ grains are transformed into an $\alpha / \beta$ lamellar structure, implying that diffusion takes place and that the alloying elements partition between the $\alpha$ and $\beta$ regions, such that 
the $\alpha$ stabilizing elements accumulate in the $\alpha$ lamellae and $\mathrm{V}$ and $\mathrm{Fe}$ in $\beta$. This redistribution of alloying elements stabilizes the $\beta$ phase against transformation in $\alpha^{\prime}$ on cooling. It is suggested that, in the present case, the redistribution during slow cooling has been sufficient to stabilize $\beta$ during CT at $77 \mathrm{~K}$.

The case of $\mathrm{Gu}$ et al. may help understanding the stabilization phenomenon and the parameters that influence it. Gu et al. describe the condition of their material subjected to CT as "annealed". Only few details are reported of the annealing treatment. Additional details can only be guessed. Firstly, the microstructure was fine in all cases, as an indication that the annealing temperature did not exceed $1100 \mathrm{~K}$. Moreover, the material contains a significant fraction of retained $\beta$, and the $\beta$ regions was either equi-axed [15, 18], or $\beta$ was present as narrow bands at the $\alpha$ boundaries [14]. The elongation of the $\beta$ regions indicates a (particularly) low cooling rate from the annealing temperature to room temperature [30-32], much slower than applied in the present work. Common sense suggests that, during (very) slow cooling, the phase fractions equilibrate and the alloying elements partition between $\alpha$ and $\beta$ to approach equilibrium conditions. Nevertheless, partitioning is possible down to, say, 950-900 K. At temperatures lower than $900 \mathrm{~K}$, diffusion in $\alpha$ is very sluggish and repartitioning during continued cooling conditions is difficult to imagine. At this stage, the microstructure of the material is frozen and can evolve only by diffusionless transformation of $\beta$ into $\alpha^{\prime}$ on continuous cooling. The stability of the retained $\beta$ regions against diffusionless transformation into $\alpha^{\prime}$ can be estimated based on the chemical composition of $\beta$ evaluated at 950-900 K in the equilibrium conditions. As follow from Fig. 9(d), equilibrium condition in the interval $950-900 \mathrm{~K}$ yields $\mathrm{Ms}<119 \mathrm{~K}$, which corresponds fairly well with the temperature interval swept during CT, i.e. 77-300 K. Consequently, slow cooling from the annealing temperature stabilizes the $\beta$ phase, which is retained at room temperature. Nevertheless, the stabilization is expected to be insufficient to suppress the $\beta \rightarrow \alpha^{\prime}$ transformation during CT. Consequently, it is not surprising that $\mathrm{Gu}$ et al. observed a reduction of the $\beta$ phase during $\mathrm{CT}$ of their samples. A martensitic transformation is associated with a shape strain. It is anticipated that the shape strain associated with the transformation generated crystallographic defects in the material, as reported by Gu et al.

In our work, retained $\beta$ remained stable during $\mathrm{CT}$, in spite of a, supposedly, faster cooling. The following mechanism is suggested to explain the redistribution of the alloying elements during (moderately) slow cooling. During cooling, repartition of the alloying elements occurred between the $\alpha$ and $\beta$ lamellae: elements with high diffusion rates, i.e. $\mathrm{O}, \mathrm{N}$ and $\mathrm{Fe}$, redistribute completely, whereas the redistribution of $\mathrm{V}$ and $\mathrm{Al}$ is somehow limited. The stability of the $\beta$ lamellae is consequently low as compared to equilibrium conditions; because of the low stability, the $\beta$ lamellae converted into $\alpha$ at high temperatures by, for example, a massive transformation. Only very small regions of beta are retained in the microstructure at high temperatures and could enrich in $\beta$ stabilizing elements upon further cooling. Because of its low fraction, lower than expected from equilibrium conditions, the $\beta$ regions enriched in $\beta$ stabilizing elements during cooling to a much larger extend as compared to expectation based on equilibrium calculations. It follows that the fraction of retained $\beta$ at room temperature is very low, but the thermal stability of the $\beta$ regions is very high, well beyond the stability obtained upon slow cooling. Consequently, no $\beta \rightarrow \alpha^{\prime}$ transformation occurs during CT. In absence of $\beta$ to $\alpha^{\prime}$ martensitic transformation during $\mathrm{CT}$, no other effect of $\mathrm{CT}$ on the microstructure is observed, implying that the $\beta \rightarrow \alpha^{\prime}$ is precondition for the effectiveness of CT.

\section{Conclusions}


In this study, commercial Ti-6Al-4V was heat treated at various temperatures in the range 1000$1250 \mathrm{~K}$ followed by (moderately) slow cooling to room temperature at an average rate of approx. $1 \mathrm{~K} . \mathrm{s}$ 1. Cryogenic treatment was carried out in boiling nitrogen for different storage times to investigate the effect of CT on phase transformation, microstructure evolution and hardness of Ti-6Al-4V. Synchrotron $\mathrm{X}$-ray diffraction was performed for quantitative phase analysis of the phase fractions and to reveal possible variations of the material microstructure at the nano-scale. The following conclusions can be drawn:

(1) After annealing and cooling to room temperature, $\alpha$ and $\beta$ were the only phases present in the material.

(2) The annealing temperature had an influence on the fraction of $\beta$, on the scale of the microstructure and on the microstructural features that could be observed in the material. Overall, an increase in annealing temperature coarsen the microstructure and increases the fraction of retained $\beta$.

(3) Neither the annealing temperature, nor the subsequent $\mathrm{CT}$ with different soaking times had a significant influence on the hardness of Ti-6Al-4V.

(4) CT had no influence on the microstructure of specimens independently of the applied CT parameters.

(5) The lack of effects of CT on the scale of the microstructure is interpreted in terms of pronounced stability of the retained $\beta$ after the applied high temperature conditions. The high $\beta$ stability is caused by a significant partitioning of the alloying elements during (moderately) slow cooling from the annealing temperature.

(6) Thermodynamic calculations could be used to reconcile the results obtained herein with other findings reported in the literature.

\section{References}

[1] M.J. Donachie, Titanium: a technical guide, ASM international, 2000.

[2] M. Villa, M.F. Hansen, M.A.J. Somers, Martensite formation in Fe-C alloys at cryogenic temperatures, Scripta Mater, 141 (2017) 129-132.

[3] S.G. Fletcher, B.L. Averbach, M. Cohen, The Dimensional Stability of Steel .2. Further Experiments on Subatmospheric Transformations, T Am Soc Metal, 40 (1948) 703-727.

[4] C.H. Surberg, P. Stratton, K. Lingenhole, The effect of some heat treatment parameters on the dimensional stability of AISI D2, Cryogenics, 48 (2008) 42-47.

[5] R.F. Barron, Cryogenic Treatment of Metals to Improve Wear-Resistance, Cryogenics, 22 (1982) 409-413.

[6] D.N. Collins, Deep cryogenic treatment of tool steels: A review, Heat Treat Met, 23 (1996) 40-42.

[7] F. Meng, K. Tagashira, R. Azuma, H. Sohma, Role of eta-carbide precipitations in the wear resistance improvements of Fe-12Cr-Mo-V-1.4 C tool steel by cryogenic treatment, ISIJ international, 34 (1994) 205210.

[8] D. Yun, X.P. Lin, H.S. Xiao, Deep cryogenic treatment of high-speed steel and its mechanism, Heat Treat Met, 25 (1998) 55-59.

[9] D.M. Lal, S. Renganarayanan, A. Kalanidhi, Cryogenic treatment to augment wear resistance of tool and 
die steels, Cryogenics, 41 (2001) 149-155.

[10] D. Das, A.K. Dutta, K.K. Ray, On the enhancement of wear resistance of tool steels by cryogenic treatment, Phil Mag Lett, 88 (2008) 801-811.

[11] V.G. Gavriljuk, V.A. Sirosh, Y.N. Petrov, A.I. Tyshchenko, W. Theisen, A. Kortmann, Carbide Precipitation During Tempering of a Tool Steel Subjected to Deep Cryogenic Treatment, Metall Mater Trans A, 45a (2014) 2453-2465.

[12] A. Bensely, S. Venkatesh, D.M. Lal, G. Nagarajan, A. Rajadurai, K. Junik, Effect of cryogenic treatment on distribution of residual stress in case carburized En 353 steel, Materials Science Engineering: A, 479 (2008) 229-235.

[13] S. Neelakantan, P. Rivera-Díaz-del-Castillo, S. van der Zwaag, Prediction of the martensite start temperature for $\beta$ titanium alloys as a function of composition, Scripta Materialia, 60 (2009) 611-614.

[14] K. Gu, J. Wang, Y. Zhou, Effect of cryogenic treatment on wear resistance of Ti-6Al-4V alloy for biomedical applications, Journal of the Mechanical Behavior of Biomedical Materials, 30 (2014) 131-139.

[15] K. Gu, H. Zhang, B. Zhao, J. Wang, Y. Zhou, Z. Li, Effect of cryogenic treatment and aging treatment on the tensile properties and microstructure of Ti-6Al-4V alloy, Materials Science Engineering: A, 584 (2013) 170-176.

[16] K. Gu, B. Zhao, Z. Weng, K. Wang, H. Cai, J. Wang, Microstructure evolution in metastable $\beta$ titanium alloy subjected to deep cryogenic treatment, Materials Science Engineering: A, 723 (2018) 157-164.

[17] L. Xu, Metastable Beta Titanium Alloys: Tuning the Beta Phase Stability and Low-Temperature Martensitic Transformation of Metastable Beta Titanium Alloys, diss., Delft University of Technology, 2015.

[18] K. Gu, Z. Li, J. Wang, Y. Zhou, H. Zhang, B. Zhao, W. Ji, The Effect of Cryogenic Treatment on the Microstructure and Properties of Ti-6Al-4V Titanium Alloy, Mater Sci Forum, 747 (2013) 899-903.

[19] J. Tran, Titanium by design: TRIP titanium alloy, diss., Northwestern University, 2009.

[20] Y. Lee, G. Welsch, Young's modulus and damping of Ti-6Al-4V alloy as a function of heat treatment and oxygen concentration, Materials Science Engineering: A, 128 (1990) 77-89.

[21] Z. Liu, G. Welsch, Effects of Oxygen and Heat-Treatment on the Mechanical-Properties of Alpha and Beta Titanium-Alloys, Metall Trans A, 19 (1988) 527-542.

[22] R. Pederson, Microstructure and Phase transformation of Ti-6Al-4V, diss., Luleå tekniska universitet, 2002.

[23] J.O. Andersson, T. Helander, L. Höglund, P. Shi, B. Sundman, Thermo-Calc \& DICTRA, computational tools for materials science, Calphad, 26 (2002) 273-312.

[24] C. Genzel, I.A. Denks, J. Gibmeler, M. Klaus, G. Wagener, The materials science synchrotron beamline EDDI for energy-dispersive diffraction analysis, Nucl Instrum Meth A, 578 (2007) 23-33.

[25] B.C. Giessen, G.E. Gordon, X-ray diffraction: new high-speed technique based on X-ray spectrography, Science 159, (1968) 973-975.

[26] Standard, A. S. T. M., Standard practice for $x$-ray determination of retained austenite in steel with near random crystallographic orientation, American Society for Testing and Materials, 2003.

[27] V. Gundyrev, V. Zel'dovich, X-ray diffraction determination of root-mean-square displacements of atoms in B2 and R phases of titanium nickelide, The Physics of Metals and Metallography, 103 (2007) 489-498.

[28] F. Niessen, Phase Transformations in Supermartensitic Stainless Steels, PhD Dissertation, Kgs. Lyngby, 2018

[29] G. Williamson, W. Hall, X-Ray line broadening from filed Aluminium and Wolfram, Acta Metall. 1 (1953) 22-31.

[30] T. Ahmed, H.J. Rack, Phase transformations during cooling in alpha+beta titanium alloys, Mat Sci Eng a- 
Struct, 243 (1998) 206-211.

[31] R. Dąbrowski, The kinetics of phase transformations during continuous cooling of the Ti6Al4V alloy from the single-phase $\beta$ range, Arch Metall Mater, 56 (2011) 703-707.

[32] L. Gerd, J. Williams, Titanium, Springer, 2007. 


\section{Figures captions}

Fig. 1. Schematic illustration of the applied thermal cycles.

Fig. 2. Light optical micrographs (LOM) of Ti-6Al-4V upon application of the following thermal treatments: (a) $1000 \mathrm{~K} \_U T$, (b) $1050 \mathrm{~K} \_U T$, (c) $1100 \mathrm{~K} \_U T$, (d) $1150 \mathrm{~K} \_U T$, (e) $1200 \mathrm{~K} \_U T$ and (f) $1250 \mathrm{~K} \_$UT.

Fig. 3. Light optical micrographs (LOM) of cryo-treated Ti-6Al-4V: (a) 1000K_CT1D, (b) 1050K_CT1D, (C) 1100K_CT1D, (d) 1150K_CT1D, (e) 1200K_CT1D and (f) 1250K_CT1D.

Fig. 4. Vickers hardness of Ti-6Al-4V for the various heat treatment conditions measured applying 0.5 $\mathrm{Kg}$ weight and plotted versus the annealing temperature sol_T. Error bars refers to the standard deviation of 10 measurements performed over 2 distinct, identically treated, samples.

Fig. 5. Synchrotron X-ray diffraction (S-XRD) spectrums as acquired for the present investigation.

Fig. 6. Fraction of retained $\beta$ as measured by S-XRD for the various treatment conditions and plotted versus the annealing temperature sol_T. Error bars refers to the standard deviation of 2 measurements performed on 2 distinct, identically treated, samples.

Fig. 7. Lattice parameters of the $\beta$ and $\alpha$ phases as measured by S-XRD for the various treatment conditions and plotted versus the annealing temperature sol_T.. Error bars refers to the standard deviation of 2 measurements performed on 2 distinct, identically treated, samples.

Fig. 8. Evaluation of the sample microstructure based on the width of the various khl reflections. (a) Example of Williamson-Hall plot where the Integral Breath Ib of the fitted peaks profiles is plotted versus the position of the hkl reflection on the energy scale E. Data refers to samples annealed at 1250 $\mathrm{K}$ : empty symbols stand for the $\beta$ reflections, full symbol for the $\alpha$ ones. (b) Intercept of the linear fit with the $y$ axis for the various treatment conditions. (c) Slope of the linear fit for the various treatment conditions. Error bars refers to the standard deviation of 2 measurements performed on 2 distinct, identically treated, samples.

Fig. 9. Equilibrium calculations obtained with Thermo-Calc ${ }^{\mathrm{TM}}$ software based on the chemical composition reported in Fig. 1 and related Ms temperatures [17]. (a) The mass fraction of phases in Ti6Al-4V plotted versus temperature T. (b) Composition of $\alpha$ at equilibrium plotted versus temperature T. (c) Composition of $\beta$ at equilibrium plotted versus temperature T. (d) Ms temperature for the calculated composition of $\beta$ plotted versus temperature $\mathrm{T}$. 


\section{Tables captions}

Table 1. Chemical compositions of titanium Ti-6Al-4V (wt.\%).

Table 2. Details of treatment group of $1000 \mathrm{~K}$-annealing specimens.

Table 3. $\mathrm{R}$ values calculated for the various hkl reflections and used for quantitative phase analysis.

Table 1

\begin{tabular}{llllllllll}
\hline Grade & $\mathrm{Ti}$ & $\mathrm{Al}$ & $\mathrm{V}$ & $\mathrm{C}$ & $\mathrm{O}$ & $\mathrm{N}$ & $\mathrm{H}$ & $\mathrm{Fe}$ & $\mathrm{Y}$ \\
\hline Ti-6Al-4V & Bal. & 6.21 & 3.8 & 0.03 & 0.15 & 0.01 & 0.005 & 0.07 & 0.002 \\
\hline
\end{tabular}

Table 2

\begin{tabular}{|c|c|c|}
\hline Group index & Annealing & CT \\
\hline $1000 \mathrm{~K} \_U T$ & & Untreated \\
\hline 1000K_CT5M & & $77 \mathrm{~K} / 5 \mathrm{~min}$ \\
\hline 1000K_CT1H & $1000 \mathrm{~K} / 5.5 \mathrm{~h}$ & $77 \mathrm{~K} / 1 \mathrm{hr}$ \\
\hline 1000K_CT1D & & $77 \mathrm{~K} / 1$ day \\
\hline
\end{tabular}

Table 3

\begin{tabular}{cccccccccc}
\hline Phase & \multicolumn{9}{c}{$\alpha$} \\
\hline$(\mathrm{hkl})$ & $(100)$ & $(101)$ & $(102)$ & $(110)$ & $(200)$ & $(112)$ & $(201)$ & $(110)$ & $(200)$ \\
\hline $\mathrm{R}$ & 17.85 & 60.97 & 5.75 & 4.72 & 0.49 & 3.40 & 2.32 & 145.2 & 13.20 \\
\hline
\end{tabular}




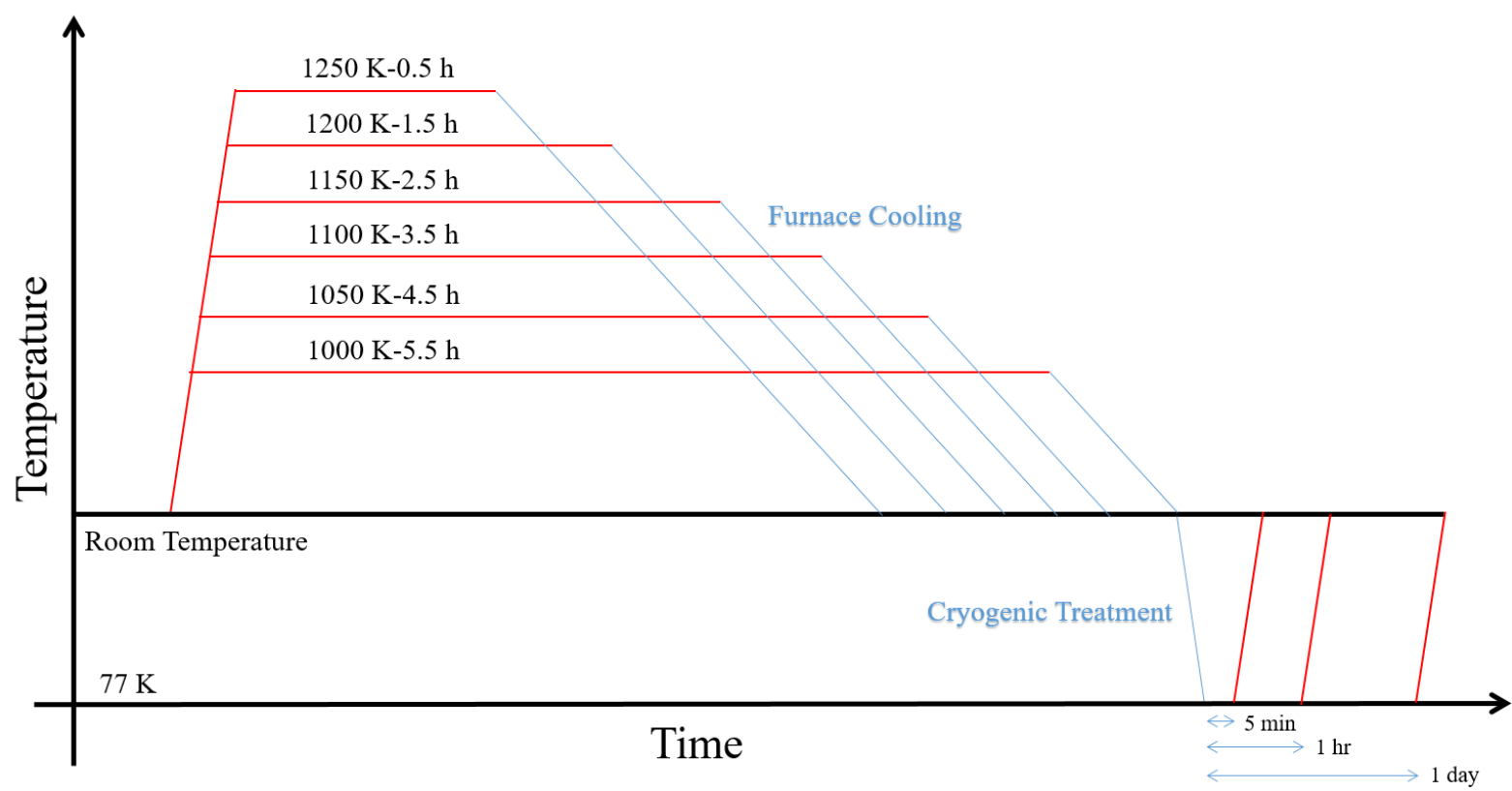

Fig. 1 

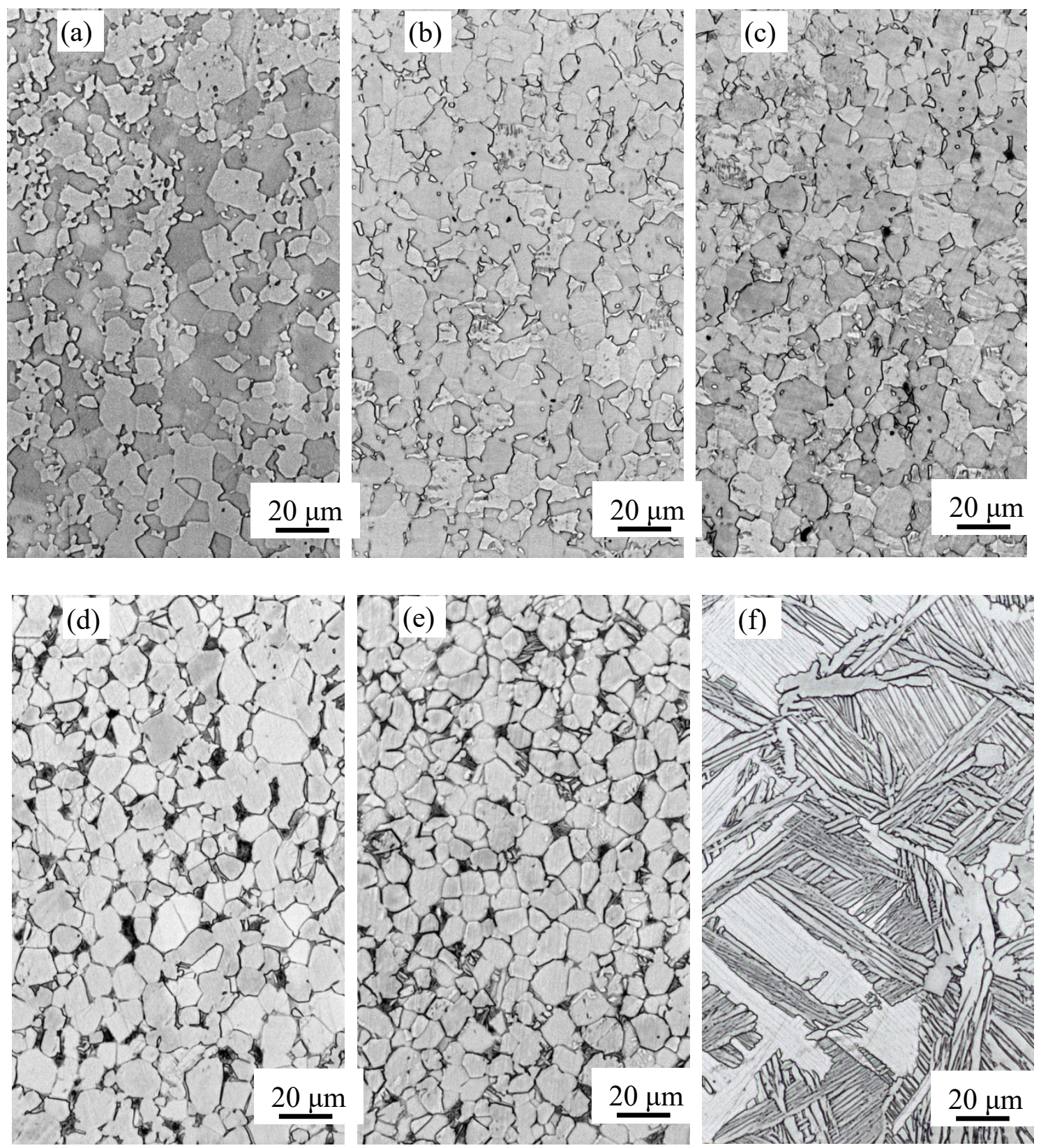

Fig. 2 

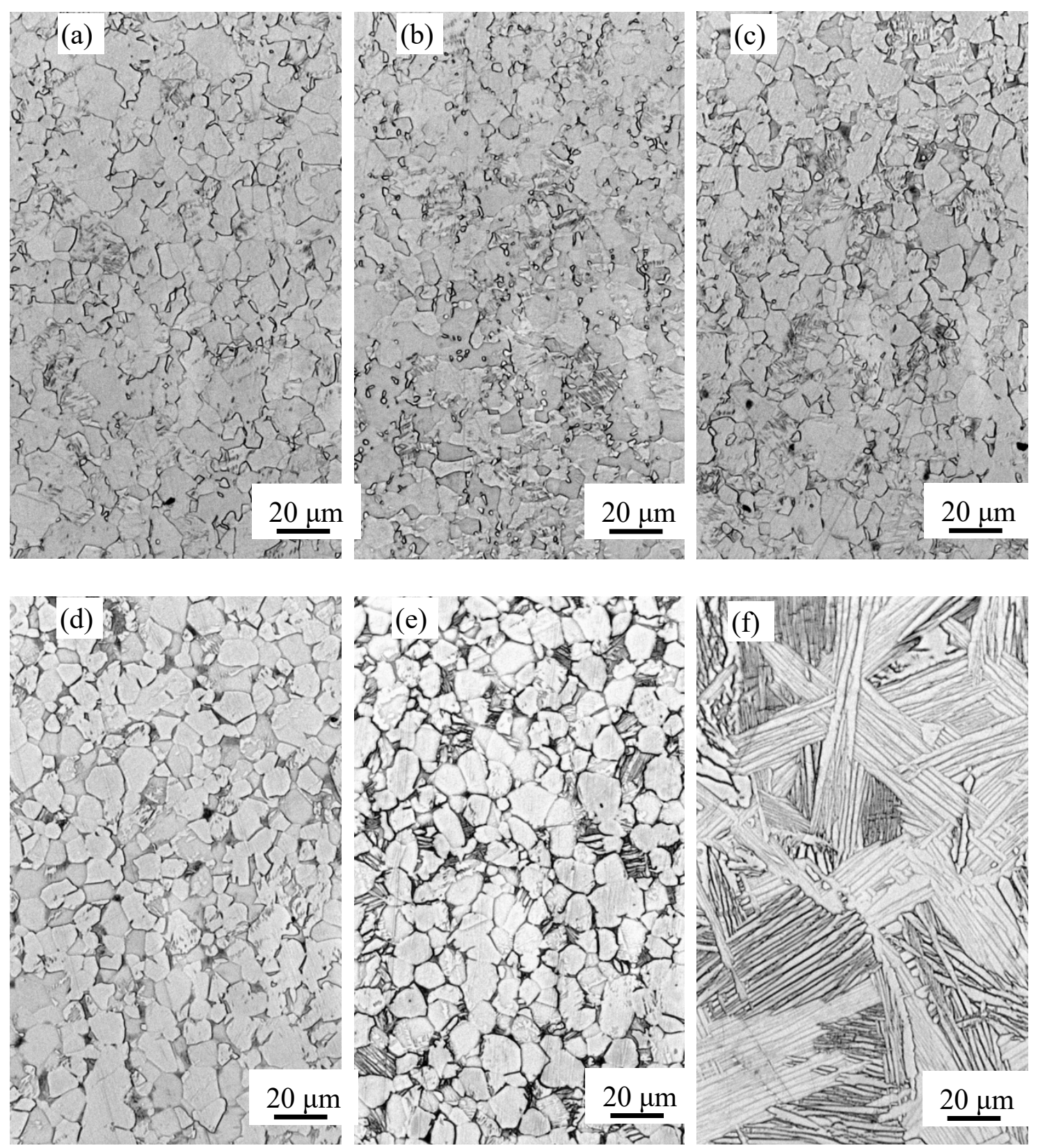

Fig. 3 


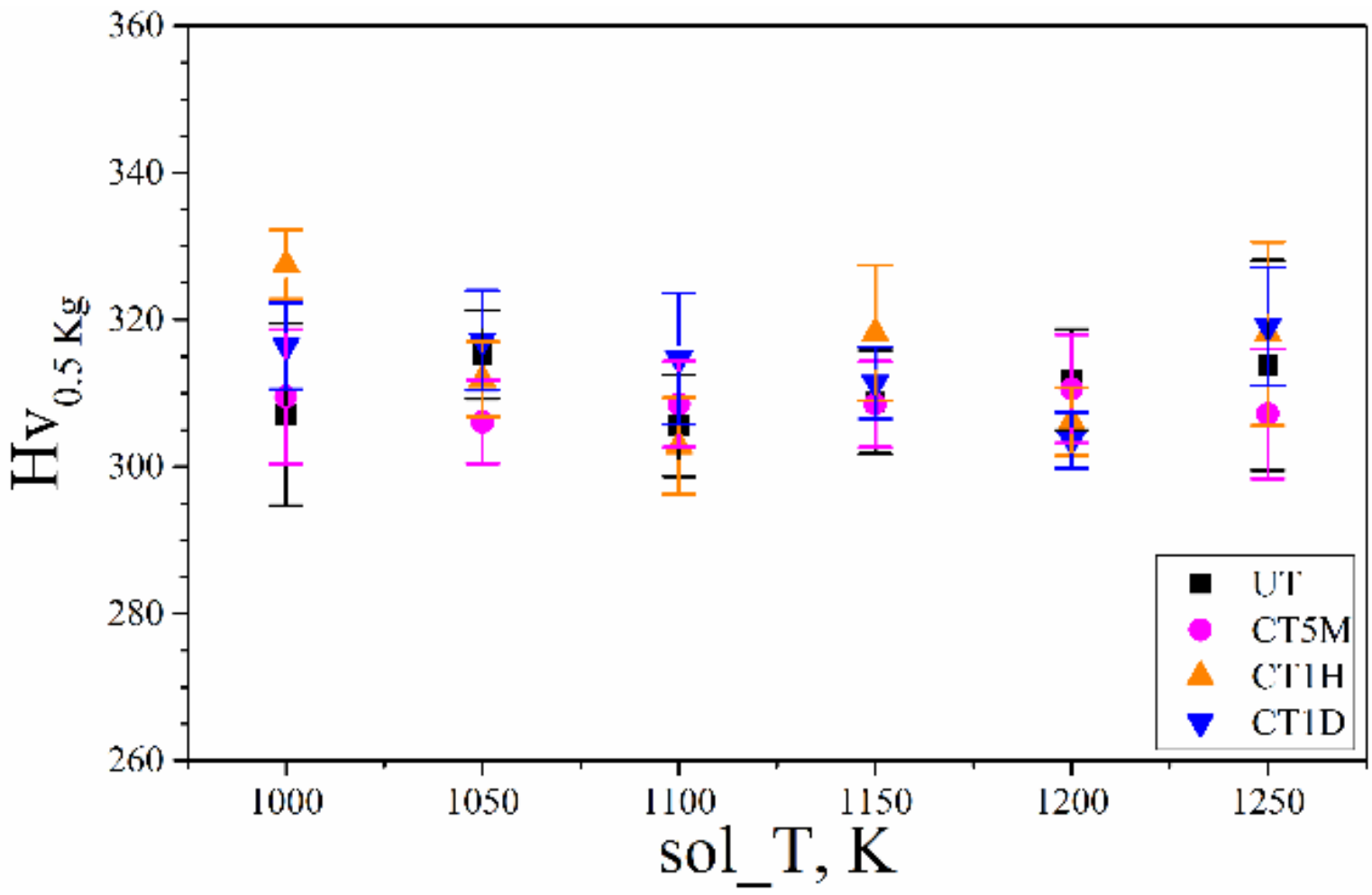

Fig. 4

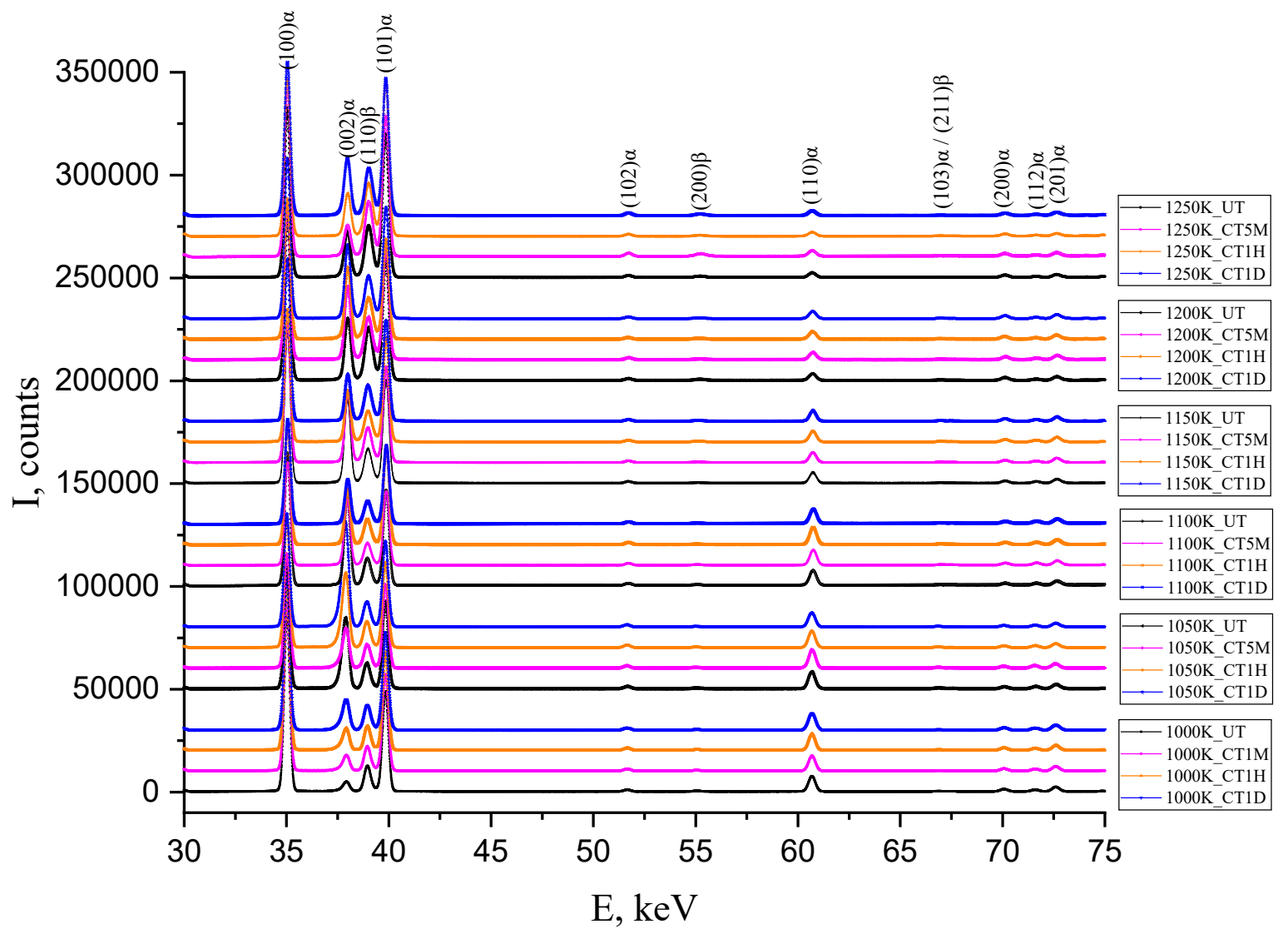

Fig. 5 


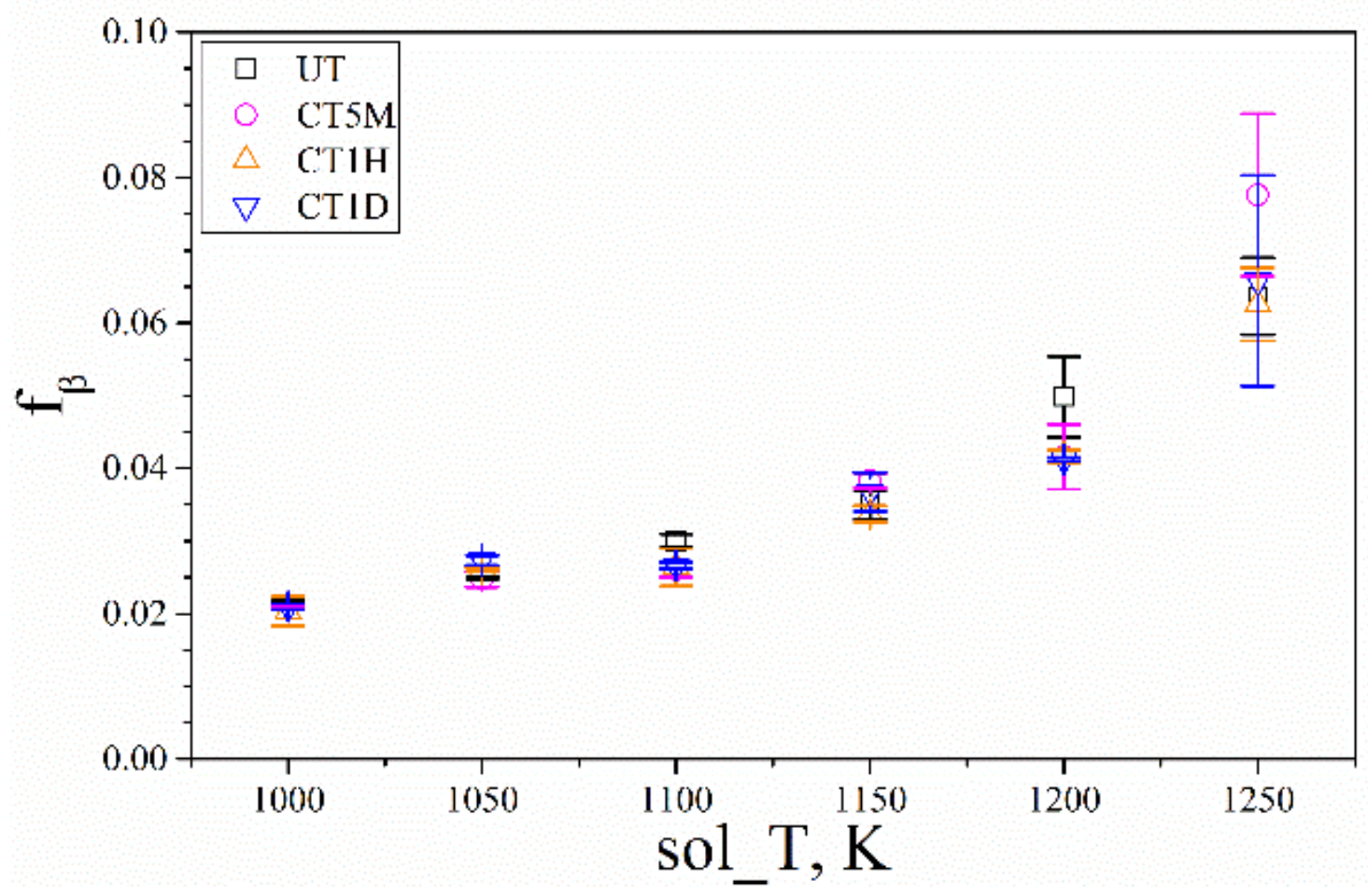

Fig. 6

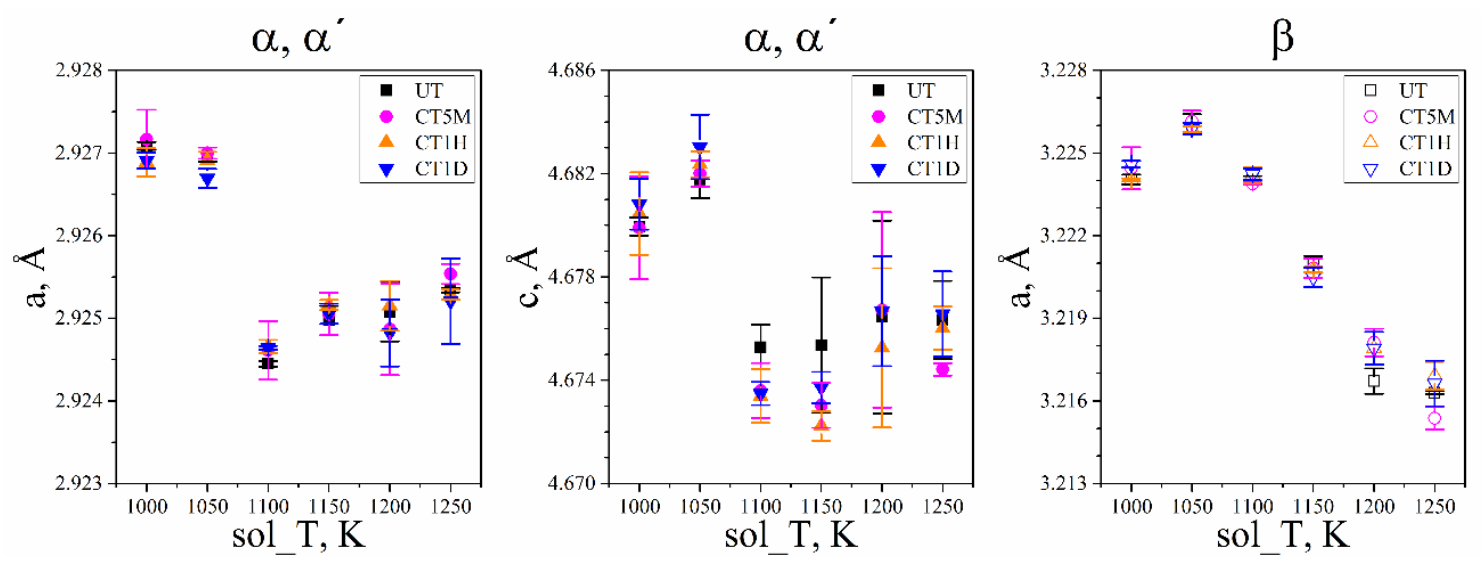

Fig. 7 

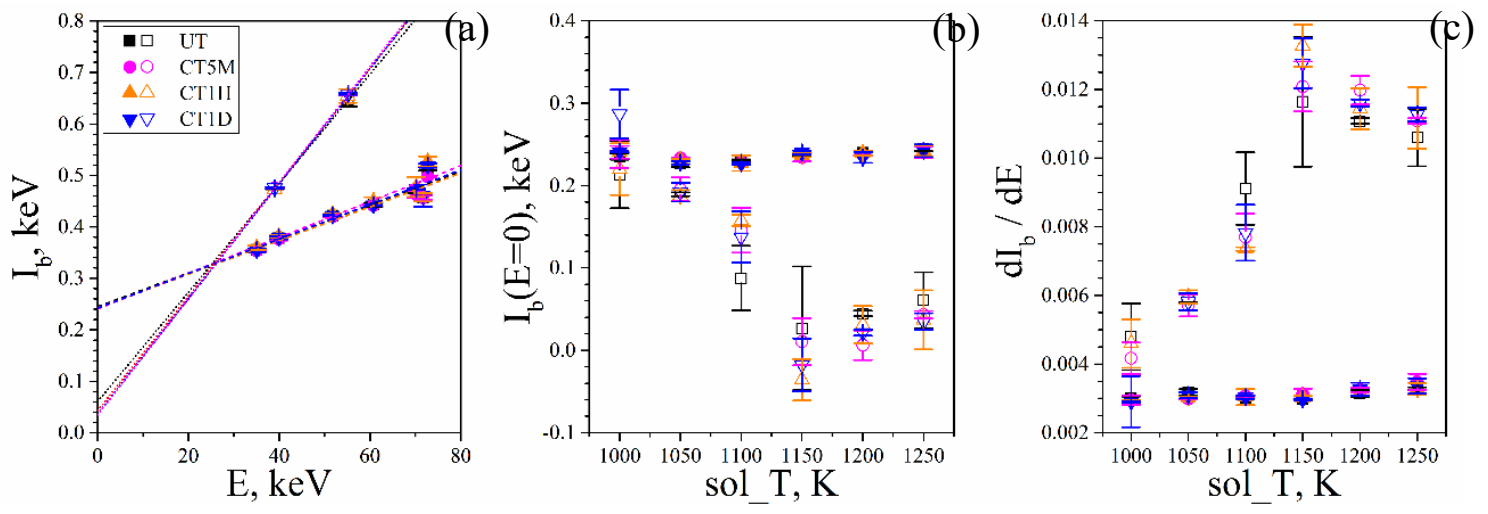

Fig. 8
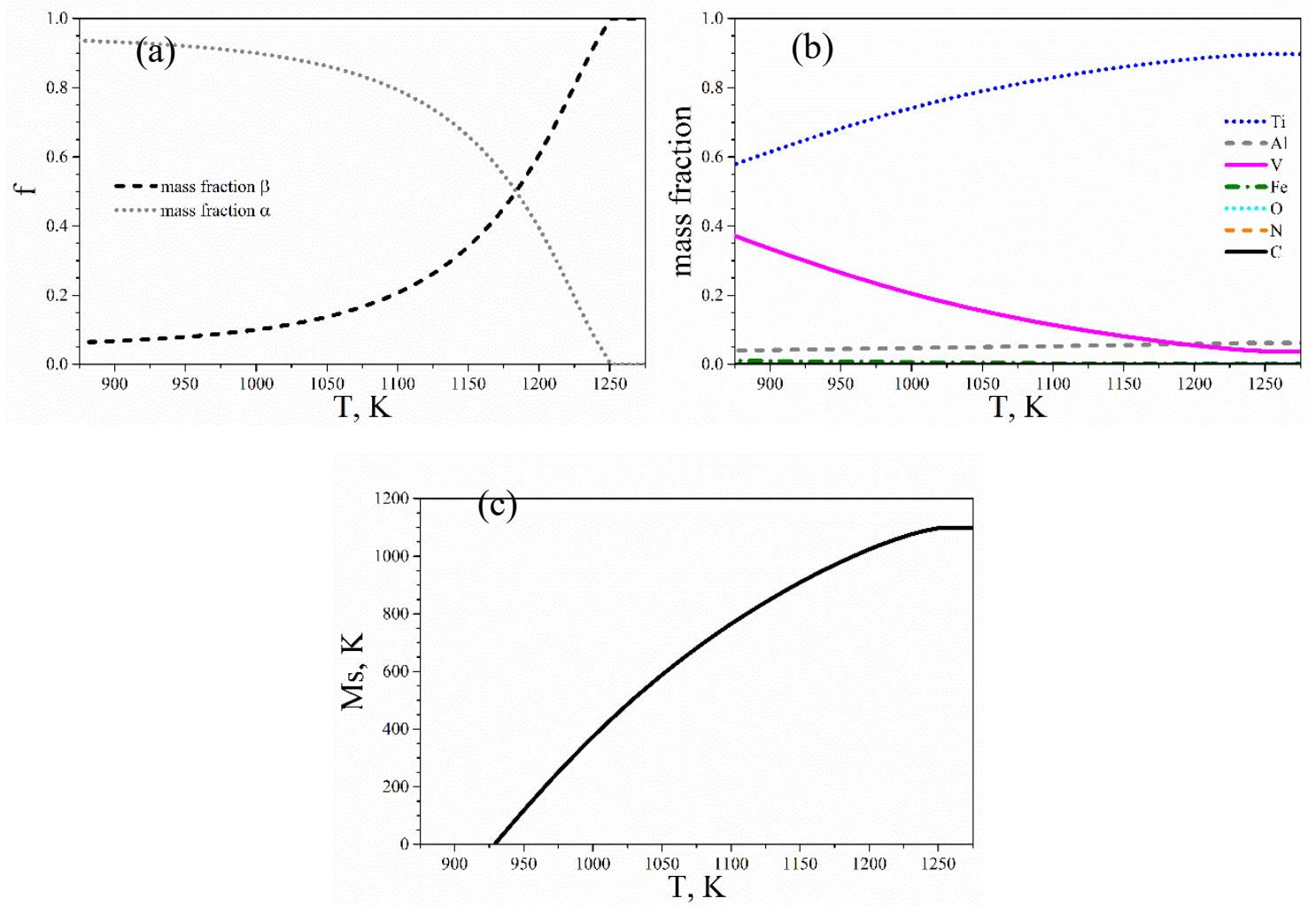

Fig. 9 